\title{
TRANSFERENCIAS DE INGRESOS A LOS HOGARES EN ARGENTINA
}

\section{INCOME TRANSFERS TO THE HOUSEHOLDS IN ARGENTINA}

\section{Pilar Arcidiácono*}

\author{
RESUMEN
}

Este artículo analiza las medidas orientadas a transferir ingresos a los hogares (con adultos mayores y niños) en Argentina en el período 2003-2013. Para ello reconstruye estos diez años en dos grandes etapas, identificando una intermedia considerada "de transición". Este trabajo sostiene que un análisis sobre el conjunto de transferencias de ingresos debe detenerse en los mecanismos institucionales que posibilitaron el incremento de la cobertura para pensar no solo la capacidad para sostenerla en el tiempo, sino las consecuencias de una oferta política fragmentada.

PALABRAS CLAVE: ARGENTINA * INGRESO POR TRANSFERENCIA * SEGURIDAD SOCIAL * NIÑOS * ANCIANOS

\section{ABSTRACT}

This article discusses the measures to transfer income to the households (elderly and children) in Argentina between 2003-2013. This reconstructs these ten years in two stages, identifying an intermediate considered "transitional". The other hypothesis guiding this paper is that an analysis of the set of income transfers should be focused on the institutional mechanisms that allowed increased coverage, which means thinking not only their ability to maintain the coverage achieved but the consequences of a fragmented political offer.

KEYWORDS: ARGENTINA * TRANSFER INCOME * SOCIAL SECURITY * CHILDREN * ELDERLY

Consejo Nacional de Ciencia y Técnica. Instituto "Ambrosio L. Gioja", Facultad de Derecho de la Universidad de Buenos Aires, Argentina.

pilar.arcidiacono@gmail.com 


\section{INTRODUCCIÓN ${ }^{1}$}

Una mirada global sobre el período que transcurre en Argentina entre 2003 y 2013 debería destacar la recuperación del empleo $y$ el aumento de la cobertura en materia de transferencias de ingresos a los hogares cuyos miembros están o han estado débilmente integrados en el mercado formal. Esto último ha tenido lugar tanto para los adultos mayores (a través de los incrementos de los montos de las jubilaciones, el crecimiento sostenido de las Pensiones No Contributivas (PNc) en todos sus formatos, el establecimiento de la movilidad jubilatoria y el Plan de Inclusión Previsional del 2005), como para los niños, niñas y adolescentes (a través de la creación de la Asignación Universal por Hijo en 2009, la Asignación Universal por Embarazo en 2011 y algunas modificaciones en el sistema de asignaciones familiares para trabajadores asalariados). Como resultado final, a simple vista, se logró en ambos grupos etarios aproximadamente entre $80 \%$ y $90 \%$ de cobertura ${ }^{2}$.

1 La investigación que dio lugar a este artículo se enmarca dentro del trabajo sostenido como investigadora formada del Grupo de Trabajo Interdisciplinario "Derechos Sociales y Políticas Públicas" de la Universidad de Buenos Aires (UBA) y del proyecto interdisciplinario (UBACYT) "Brechas de bienestar y marginación social en Argentina" en el marco del Programa de Marginaciones Sociales de la UBA. La metodología estuvo basada en técnicas cualitativas combinando una serie de entrevistas a informantes calificados junto con el análisis de distintos documentos públicos e informes sobre la materia, pedidos de información realizados en el marco de este trabajo bajo el Decreto 1172/03 de Acceso a la Información Pública. Asimismo se nutrió con material obtenido a través de la participación en espacios de discusiones sociales y académicas sobre la temática.

2 La escritura de este artículo no escapa a los problemas de producción y difusión de información que tienen lugar en Argentina vinculados con la pérdida de confiabilidad del Instituto Nacional de Estadísticas y Censos (INDEC), luego de su intervención en 2007. Como señala Kessler (2014), esto generó una ausencia de parámetros comunes de referencia sobre inflación y pobreza a tal grado que, por ejemplo, en 2013, en la tasa de pobreza oficial y la acuñada por centros de investigación que presentan datos alternativos llegan a 20
Este artículo reconstruye estos diez años en dos grandes períodos, identificando uno intermedio considerado "de transición". Parte de sostener la existencia de medidas singulares en materia de transferencias de ingresos $y$ un conjunto de resistencias políticas y discursivas que fueron adquiriendo sentidos específicos a través de la década. La otra hipótesis que guía este trabajo es que un análisis sobre el conjunto de transferencias de ingresos debe detenerse en los mecanismos institucionales que posibilitaron el incremento de la cobertura, lo que implica tener en cuenta dos aspectos. Por un lado, un panorama al menos incierto a mediano/largo plazo en lo que respecta a la continuidad de estas medidas y sobre todo en su capacidad para mantener los niveles de cobertura alcanzados. Por otro, las consecuencias propias de un esquema de gestión de riesgos sociales que consolida su carácter dual con diferencias sustantivas entre prestaciones contributivas y no contributivas, que más o menos explícitamente mantiene el patrón histórico "trabajocéntrico" de la provisión de bienestar en Argentina.

Para comprender el contexto nacional es importante comprender que si bien, el régimen de bienestar argentino de mediados de los años 40 , fue caracterizado por la combinación de diferentes principios aseguradores de riesgos sociales, implicando una mayor relevancia del esquema contributivo, seguido de un conjunto de prestaciones universales sobre todo en el campo educativo y luego en el sector salud, con el fin de completarse con medidas focalizadas de carácter más residual para aquellos que presentaban diversas situaciones de vulnerabilidad (Isuani 1992).

El componente contributivo implicó la vía de acceso a la cobertura médica, a las asignaciones familiares correspondientes en el caso de tener una familia o hijos a cargo - que como indica Pautassi (2005), estaban en cabeza del varón proveedor que brindaba protecciones al resto de la familia-, al seguro por desempleo

puntos, aspecto que dificulta llegar a consensos. Se decidió trabajar solo con base en fuentes oficiales de información sin desconocer que la disparidad entre las fuentes dificulta enormemente la tarea de reconstrucción analítica. 
en el caso de ser despedidos y a la jubilación cuando se producía el retiro del mercado laboral. A esto se le suman vacaciones pagas, aguinaldo y cobertura por accidentes de trabajo y la percepción de salarios no menores al valor del Salario Mínimo Vital y Móvil vigente, así como a las remuneraciones establecidas en los convenios colectivos y la posibilidad de asegurar ingresos a través de las pensiones a los cónyuges e hijos menores de edad. Este cuadro se completa con la afiliación sindical y sus eventuales beneficios. Más allá de las desigualdades territoriales y las distorsiones sectoriales (producto de la dinámica sindical organizada por rama y la capacidad diferencial de movilización colectiva $y$ de presión política de los distintos sectores de la economía), el funcionamiento del mercado de trabajo formal argentino con bajos niveles de desempleo y subempleo entre las décadas de los 40 y los 70, en los hechos estuvo próximo a un sistema con cobertura de aparente universalidad (Lo Vuolo y Barbeito 1998).

La evidencia empírica indica que las transformaciones de las condiciones sociales y laborales de la población iniciadas durante la etapa de "ajuste estructural" y radicalizadas luego de la crisis 2001-2002, marcan los límites de un esquema de bienestar sostenido fuertemente en el pilar contributivo, perdiendo la capacidad de cobertura y monto de las protecciones $y$ generando nuevos desafíos para el diseño de las políticas sociales. Este artículo problematizará sobre las tensiones entre estos esquemas históricos de provisión de bienestar y los nuevos riesgos sociales propios de la década analizada y sobre las últimas medidas que se tomaron para abordar esta problemática ${ }^{3}$.

\section{PRIMER PERÍODO (2003-2007): "TRABAJOCENTRISMO" Y REFORMAS PREVISIONALES}

Un primer período transcurre entre 2003 y 2007, momento en el que la intervención estatal en el campo de las políticas sociales fue consolidándose paulatinamente en las siguientes líneas: 1) en un contexto de recuperación de

3 Para una mirada sobre este mismo período, cfr. Danani y Grassi, 2013. la actividad económica, se generaron medidas destinadas a los trabajadores asalariados formales. Este abordaje denominado "trabajocéntrico" implicó una diferenciación política y discursiva respecto de la década anterior (Arcidiácono 2012); 2) en el corto plazo, un conjunto de programas sociales, (algunos iniciados previamente) caracterizados por un bajo e inamovible monto $y$ un ingreso altamente restringido, fueron encargados de abordar las situaciones de las personas en condición de pobreza y falta de empleo bajo un supuesto de "transitoriedad" de las situaciones que les daban sentido ${ }^{4}$; 3 ) en paralelo al cierre de la inscripción y los consecuentes problemas de accesibilidad de los programas y al déficit de cobertura del sistema previsional, se produjo la reapertura de las Pensiones No Contributivas (PNc) en la órbita del Ministerio de Desarrollo Social (mDs) con un acceso a través del tradicional test de recursos y hacia mediados de este período, el surgimiento de "Plan de Inclusión Previsional" a cargo de la

4 El Plan Jefas y Jefes de Hogar Desocupados se implementó en la órbita del Ministerio de Trabajo, Empleo y Seguridad Social, respondiendo a la situación social que planteó la crisis 2001-2002 durante la gestión del presidente Eduardo Duhalde. En pocos meses cubrió casi dos millones de personas. Consistía en una prestación masiva que transfería \$150 (us\$ 50) a los hogares, sin que el monto implique variaciones por la cantidad de hijos, a cambio del cumplimiento de las condicionalidades de salud y educación de los hijos(as) y de que los padres o las madres realizaran una contraprestación que podía ser comunitaria, educativa o en empresas por un mínimo de 4 y un máximo de 6 horas diarias. Sin embargo, cuatro meses después de la apertura se cerró la inscripción al programa y su monto quedó inamovible desde su surgimiento hasta el 2009, momento en que el programa desaparece. Hacia 2005, se migran los receptores ya inscriptos en el programa dependiendo de su grado de "empleabilidad" o "inempleabilidad" hacia el Seguro de Capacitación y Empleo o hacia el Programa Familias, respectivamente. Este último representó un típico formato de programa de transferencias condicionadas de ingresos como los existentes en la región, que no exigía una contraprestación laboral, pero sí condicionalidades en materia de salud y educación cuyas transferencias eran cercanas al programa anterior pero dependían mínimamente de la cantidad de hijos (Arcidiácono 2012). 
Administración Nacional de la Seguridad Social (ANSEs) que posibilitó el aumento más significativo de toda esta década en la cobertura de transferencias destinadas a adultos mayores.

Esta última línea de intervención será la abordada en este artículo, la cual atravesó el campo previsional (contributivo, no contributivo y "semicontributivo") y representa $\sin$ dudas el mayor cambio a nivel de cobertura en materia de transferencias en este período. Comenzando por las pNc, estas no requieren cotizaciones previas para lograr el acceso a los beneficios y se financian con recursos generales, mediante una transferencia desde la anses hacia la Comisión Nacional de Pensiones Asistenciales (CNPA) dependientes del MDs. Pueden clasificarse en tres grandes grupos. El primero son las pensiones por leyes especiales, que reconocen un mérito o realizan una reparación: dentro de ese grupo las más significativas por su número son las que se entregan a excombatientes de la Guerra de Malvinas y aquellas destinadas a familiares de desaparecidos. El segundo son las pensiones graciables cuyos beneficiarios son escogidos por los integrantes del Poder Legislativo Nacional ${ }^{5}$ y un tercer grupo (donde se concentra este artículo), el de las pensiones asistenciales, compuesto a su vez por tres tipos de prestaciones: pensiones por invalidez, pensiones a la vejez (datan de 1948 $y$ fueron creadas por la Ley nro. 13 478) y pensiones a madres de 7 ó más hijos nacidos vivos (creadas en 1990 por Ley nro. 23 746).

Uno de los puntos más controversiales de las PNC asistenciales son los requisitos para el acceso de extranjeros residentes en el país que se ubican entre 15/20 años de acuerdo al tipo de prestación, aspecto que fue cuestionado en un caso de litigio individual por la propia Corte Suprema de Justicia de la Nación, aunque no tuvo su correlato en una transformación de la política pública ${ }^{6}$. En cuanto al monto, hay disparidad

$5 \quad$ Si bien, estas prestaciones también existen en otros países, no alcanzan una cobertura tan significativa como en Argentina (Bertranou, Cetrángolo, Grushka y Casanova 2011).

$6 \quad$ La Corte se expresó a través del fallo "Reyes Aguilera, D. c/ Estado Nacional" (Resuelto el 04/09/2007). Al momento de finalizar la escri- entre las propias PNc asistenciales. Mientras que la pensión para madres de 7 o más hijos tiene un nivel similar a la jubilación mínima, las pensiones por vejez e invalidez no superan el $80 \%$ del haber mínimo (eLA 2011). Todas las pensiones cuentan con una cobertura de salud a través del Programa Federal de Salud (PRofe).

Las PNC asistenciales aumentaron sostenidamente durante 2003-2013. Dado que los programas sociales (Plan Jefas y Jefes de Hogar Desocupados y Programa Familias) tenían un ingreso restringido, las pensiones se consolidaron como una vía de acceso abierta a trasferencias de ingresos para esas situaciones particulares. Estas prestaciones tienen un carácter vitalicio y utilizan un test de recursos para identificar personas que no cuentan con ninguna otra forma de sostén personal y familiar. Sin embargo, la reglamentación no establece pautas que le permitan a la cNPA determinar en qué casos los recursos que posee el peticionante o los parientes obligados a prestar asistencia alimentaria permiten la subsistencia del grupo familiar, lo que en muchos casos se transforma en una causal de denegatoria de la solicitud (cels 2004).

Es preciso recordar que desde 1998, el acceso a estas pensiones se había suspendido por decisión gubernamental y el otorgamiento de nuevos beneficios quedó supeditado a una baja equiparable. Por lo tanto, entre 1999 y 2003, se observa un relativo estancamiento en la cobertura de las pNc. La creación en 2003 del Programa Adulto Mayor removió algunos de los obstáculos presupuestarios que impedían una mayor extensión del sistema de pensiones a la vejez (cels 2004). Si bien, el cambio comienza en este primer período (2003-2007), el aumento de las PNc de tipo asistencial fue una característica constante de toda esta década. Tomando como

tura de este artículo, se toma conocimiento de otra sentencia vinculada con la temática. Se trata de una acción impulsada por el Centro de Estudios Legales y Sociales y Centro Argentino de Refugiados, a partir de la cual el Juzgado de Primera Instancia en lo Civil y Comercial Federal nro. 5 declaró inaplicable por inconstitucional, los requisitos de 20 años de residencia para acceder a una pensión por discapacidad a un ciudadano de nacionalidad peruana que habita en Argentina (cfr. www.cels.org.ar). 
referencia a diciembre de 2003, había 183563 PNC de tipo asistencial mientras que en junio de 2012 se alcanzó 1148608 prestaciones. Desagregando estos números, las pensiones por invalidez pasaron de 81539 a 791 150; las de madres de 7 o más hijos de 58752 a 319026 (Ministerio de Trabajo, Empleo y Seguridad Social-mTerss 2012). Mientras que las pensiones por vejez aumentaron de 38432 a 43 272, la mayoría entre 2004 y 2006. Su estancamiento se debe sobre todo al surgimiento de la moratoria previsional como opción de ingreso al sistema previsional.

Más allá de la demanda en las pensiones (sobre todo frente a los programas bloqueados), parte del incremento de la cobertura se explica por los cambios en la oferta. Cabe recordar que este instrumento ha recibido diversas críticas por sus dilaciones y sus niveles de subejecución presupuestaria, que treparon hasta el $42 \%$ en 1998 (Cels 2004). En este período se llevaron a cabo campañas y operativos a nivel municipal, también se avanzó en mecanismos de gestión de la información que mejoraron los tiempos de la tramitación y el acceso a nuevos receptores. Esta mirada sobre los cambios de la oferta explica por qué las pensiones para madres de 7 o más hijos aumentaron, mientras que entre 2003-2011 hubo una tendencia decreciente de los nacimientos cuyo número de orden es de 6 ó más hijos (Cogliandro 2013) ${ }^{7}$.

Pero en este período hay otros cambios en materia previsional motivados por los bajos niveles de cobertura en adultos mayores que, según el Libro Blanco de la Previsión Social, habría descendido aproximadamente del $76 \%$ en 1994 a un 65,5\% en 2001; es decir, con un ritmo de caída de 1,5 puntos porcentuales al año (мтеYss 2003). Esto se debe a diversos factores que pueden sintetizarse de la siguiente manera:

...el agotamiento del excedente previsional propio de las primeras etapas de su desarrollo (al ser destinado al financiamiento del Estado, en funciones

$7 \quad$ En 2003, el 7,2\% de los nacidos vivos correspondían a niños de madres que tenían 6 hijos o más, es decir, 49965 niños o niñas, mientras que en el año 2011 se redujo al 4,2\% (32 190 niños o niñas) (Cogliandro 2013). diferentes de la previsión social); la creciente informalidad laboral y el incumplimiento de las obligaciones previsionales (evasión), que deterioraban la tasa de dependencia del sistema; los cambios en la estructura demográfica (graduales descensos de la fecundidad y de la mortalidad en todos los tramos etarios), con el consiguiente envejecimiento de la población; debilidades institucionales (que otorgaban, por ejemplo, una suma considerable de beneficios por invalidez y permitían la multiplicación de regímenes especiales), además de otros factores macroeconómicos (inflación), así como el uso de instrumentos de política previsional con otros fines de política macroeconómica (devaluaciones fiscales por medio de una reducción en las contribuciones patronales) (Bertranou et ál. 2011, 54).

Es por esto que el financiamiento del sistema previsional argentino requirió de fondos provenientes de los impuestos generales, es decir, por fuera de los aportes y contribuciones de los asalariados. De todas formas, cabe señalar que con anterioridad a los años 90 y en diferentes períodos, se incluyeron recursos provenientes del Tesoro Nacional y de la asignación específica de una porción del Impuesto al Valor Agregado (Iva) e impuestos internos sobre tarifas de combustibles, gas y teléfonos (Isuani y San Martino 1995). Sin embargo, en el período que va desde 1999 a 2001, la incidencia fue mayor y este financiamiento alcanzó casi el $70 \%$, incidiendo en los posteriores problemas de solvencia fiscal del sistema previsional. De hecho, la estructuración del régimen de capitalización, la recesión desde 1998 y la crisis del período 2001-2002, profundizaron el problema del desfinanciamiento del sistema, en la medida que se incrementaron los niveles de desocupación, se redujo el nivel de cumplimiento de las obligaciones previsionales y se deterioró la capacidad adquisitiva de los haberes jubilatorios. 
Es en este marco que se tomaron algunas medidas previsionales en el período 2003-2007 .

Más concretamente, a comienzos de 2005, se creó el "Plan de Inclusión Previsional" (Ley nro. 25 994) que estableció la moratoria previsional. Este instrumento brindó la posibilidad de acceder a un beneficio jubilatorio teniendo la obligación de cumplir con el pago de cuotas adeudadas a la seguridad social. Hacia diciembre de 2005 (Decreto nro. 1454/05), se permitió que los trabajadores autónomos pudieran incorporarse y se extendió este mecanismo a los derechohabientes para obtener la pensión en caso de trabajador fallecido. Como particularidad, la regularización voluntaria de la deuda permitía el reconocimiento de los años aportados hasta 1994, por lo que gradualmente se iba extinguiendo la posibilidad de uso, razón que motivó una nueva moratoria durante el 2014.

La misma ley que dio lugar a la moratoria inauguró la "Jubilación anticipada" para quienes se encontraban desempleados y contaban con los años de aportes requeridos para obtener la prestación previsional, hasta cinco años antes de la edad de jubilación (60 años para los hombres y 55 para las mujeres). Sin embargo, mientras se cubran esos años necesarios para el retiro podían obtener el 50\% del haber correspondiente (Decreto nro. 1451/06).

8 Si bien aquí se analizará el "Plan de Inclusión Previsional", existieron otras transformaciones asociadas que no están directamente vinculadas con el aumento de la cobertura pero son significativas respecto del rol del Estado en materia previsional. En 2007, la ley de presupuesto aumentó las jubilaciones. En el mismo año se modificó el Sistema Integrado de Jubilaciones y Pensiones, vigente desde 1994, manteniendo el carácter mixto del sistema, pero admitiendo el traslado, aunque restringido, entre uno y otro componente mientras que los indecisos fueron recibidos por el Régimen Previsional Público; incrementándose también el porcentaje de la prestación por permanencia del componente público. Finalmente, se creó el Fondo de Garantía de Sustentabilidad del Sistema Integrado Previsional Argentino, a fin de asegurar que los incluidos en este sistema no se constituyan en variable de ajuste en momentos en que el ciclo económico se encuentre en fases desfavorables (Arcidiácono 2012).
Entre junio de 2005 y diciembre de 2008, las jubilaciones anticipadas sumaron 45895 nuevos beneficios, mientras que las prestaciones por moratoria incorporaron al régimen contributivo a 1915730 nuevos jubilados y pensionados (Calvi y Cimillo 2010).

Con respecto a la moratoria, diversos actores la incorporan dentro de un formato denominado "semicontributivo" (мтеуss y огт 2012). Por esta vía, el propio Estado amplía la cobertura a través de una suerte de "préstamo" al beneficiario, quien luego la cancela a través de un plan de cuotas. Ficticiamente, el Estado asume y garantiza la deuda contributiva del receptor (por ejemplo, empresas que evadieron sus aportes), no la anula ni tampoco opta por una prestación bajo principio de acceso universal basado en condición de ciudadanía (como por ejemplo sucede en el caso de Renta Dignidad en Bolivia $^{9}$ ) (Arza y Chanbederian 2014).

Por su parte, este formato "semicontributivo" tiene más semejanzas con las prestaciones propias del sistema contributivo que con las Pensiones No Contributivas. Para la moratoria no es necesario un test de recursos como las PNc; se otorgan los mismos derechos de acceso a cobertura de salud $y$ asignaciones familiares que las prestaciones contributivas. A diferencia de las pNc a la vejez cuya edad mínima es de 70 años para hombres y mujeres, para la jubilación por moratoria rigen las mismas edades de retiro que en el sistema contributivo, esto es, 60 años para las mujeres y 65 para los hombres. Finalmente, el valor de las pnc por vejez e invalidez se determina como el $70 \%$ del beneficio mínimo del sistema contributivo, mientras que en las jubilaciones por moratoria, el monto que corresponde percibir a cada beneficiario depende de su historia laboral. De todas formas con relación a este último punto, el beneficio promedio

$9 \quad$ La Renta Dignidad, surgida en 2008 durante la gestión del Presidente Evo Morales, es un beneficio vitalicio, no contributivo, universal e independiente de los antecedentes laborales o circunstancias económicas particulares de los destinatarios y se otorga sin prueba de medios. Tienen derecho todos los bolivianos y bolivianas residentes en el país mayores de 60 años, excluyendo solo a quienes perciben una remuneración contemplada en el Presupuesto General de la Nación. 
de las prestaciones otorgadas en el marco de la moratoria tienen un valor cercano al beneficio jubilatorio mínimo del sistema contributivo sobre el que se realizan los descuentos convenidos para abonar las cuotas de la moratoria.

Al igual que las pNc, la moratoria terminó alcanzando mayoritariamente a las mujeres (concretamente, el 87\% del total de los receptores). La edad promedio es de 72 años y las tres cuartas partes de ellas no contaba con ningún beneficio jubilatorio previo (ELA 2011). Los resultados de la moratoria previsional constituyen un ejemplo contundente de cómo las brechas en el mercado laboral se reproducen en el sistema previsional. Más allá de que trascendieron como "jubilaciones de amas de casa", los datos oficiales indican que del total del grupo que accedió a la moratoria, el $79 \%$ estuvo inserto en el mercado de trabajo previamente $y$ de este grupo que trabajó, casi la mitad lo hizo por más de 25 años y un cuarto por menos de 10 años. Esto no hace más que dar cuenta del impacto de la informalidad al momento de cobrar una prestación previsional y la necesidad de pensar esquemas por fuera de los tradicionales esquemas contributivos. Este aspecto se intensifica en los sectores de menores recursos, de hecho los perceptores de la moratoria se concentran en el segundo y el tercer quintil (50\% vs $38 \%$ de los otros jubilados en el sistema contributivo) (мтеYss 2014).

La expansión de la cobertura previsional a través de la moratoria principalmente llamó la atención de diversos actores, como el Banco Interamericano de Desarrollo (Bosch, Melguizo y Pagé 2013) (que en uno de sus recientes informes señala que Argentina se convirtió en el segundo país en cobertura previsional de la región precedida por Bolivia). En términos de cobertura, el avance de los cambios previsionales es indiscutible $y$ atraviesa toda la década analizada. Un panorama global indica que en 2003, el 66,1\% de adultos mayores contaban con al menos una prestación pasando a $95,8 \%$ en 2010 y al 93,8\% en 2013 (caída que se debe al efecto de la baja dada la pérdida de impacto de la moratoria que permite "comprar años" hasta 1993) ${ }^{10}$.

El conjunto de cambios previsionales determinó que los recursos tributarios se redujeron del $41 \%$ de los ingresos totales de ANSES en 2003 al 33\% en 2013, manteniéndose constante los años posteriores (anses 2013). Sin dejar de destacar los niveles de cobertura, alguna literatura sobre la materia alerta sobre los posibles impactos negativos de este tipo de intervenciones en los sistemas contributivos actuales $y$ en el funcionamiento del mercado laboral, especialmente si se desarrollan en forma paralela, incluso como alternativa a los sistemas contributivos (Bertranou et ál. 2011, Bosch et ál. 2013).

Esos argumentos señalan el posible desincentivo de trabajadores de ingreso medio $y$ bajo para aportar a un sistema contributivo de pensiones frente a reiteradas repeticiones de "moratorias", lo que agravaría los problemas de equidad, financiamiento y sostenibilidad existentes. Cabe detenerse en este punto $y$ al menos poner en dudas no solo el supuesto de un caudal de información por parte de los receptores con capacidad para dirimir entre los tipos de sistemas y prestaciones, sino también señalar que una mirada que enfatice en la lógica de incentivos resta peso a la estructura productiva argentina, la cual tiende a reproducir

10 Cabe recordar que además del SIPA y las PNC existen otros regímenes nacionales que en el detalle de este artículo no son abordados (Policía Federal, Policía de Territorios Nacionales, Servicio Penitenciario, Gendarmería Nacional, Fuerzas Armadas, Prefectura Naval Argentina y Administración de Parques Nacionales) que tienen características especiales por combinar fines previsionales con un marco de retiro específico, debido a las particularidades de cada actividad. El número total de beneficiarios ha permanecido relativamente estable durante los últimos diez años, con una cifra cercana a las 180 mil personas cubiertas (Bertranou et ál. 2011). Por otra parte, respecto de las cajas previsionales de los gobiernos provinciales y municipales, así como respecto de las cajas de profesionales, lo cierto es que no se cuenta con información fácilmente disponible acerca de los beneficiarios ni de los beneficios puestos en pagos ni sobre las posibles superposiciones (Bestard, Carrasco y Pautassi 2014). 
un esquema heterogéneo con dificultades para absorber mano de obra en condiciones formales $y$ estables, aspecto que se comprobó incluso a pesar de la mejora en materia de empleo a lo largo de estos diez años ${ }^{11}$ (Salvia 2011). En todo caso, como señalan Bestard, Carrasco y Pautassi (2014), esta medida interpela al mercado de trabajo y al sistema previsional, asumiendo que cada uno de ellos presenta discriminaciones intrínsecas (de género, de clase).

\section{SEGUNDO PERÍODO (2008-OCTUBRE 2009): ENTRE EL CONFLICTO POLÍTICO Y LAS RESISTENCIAS AL UNIVERSALISMO}

Un segundo período (que se denomina de transición) transcurre entre 2008 y octubre de 2009. Si bien, hacia el 2007, la presidenta Cristina Fernández ganaba en primera vuelta electoral con más del 45\% de los votos, el 2008 estuvo atravesado por un escenario más adverso política y económicamente. Por un lado, un contexto de disputa del gobierno con el sector agropecuario al promoverse un aumento de la alícuota de los derechos de exportación de los productos del agro, lo que generó fuertes resistencias de las diferentes organizaciones que representaban este sector de la economía $y$ de otros grupos opositores que se articularon en torno a este conflicto, el cual finalizó con el rechazo del Senado a la propuesta oficialista a partir del polémico voto en disidencia del vicepresidente Julio Cobos (que constitucionalmente actuaba como Presidente de esta Cámara). Por otro lado, las repercusiones de la crisis internacional de 2008 afectaron la actividad económica, el nivel de empleo y la capacidad de consumo de la población en numerosos países del mundo. Este escenario se complementa con la primera derrota electoral

11 Coatz, García y Woyecheszen (2010) utilizan este marco y señalan que en 2006 , un $10 \%$ de la población económicamente activa trabaja en el sector moderno de la economía, un $42,2 \%$ en el sector tradicional $y$ un $47,7 \%$ en un sector de subsistencia. Esto tiene incidencia directa en el punto que se analiza sobre cobertura contributiva, ya que el primer subsistema cuenta con un $96 \%$ de participación del empleo formal, el segundo un $53 \%$ y en el tercero esa cobertura es inexistente. del oficialismo en las elecciones legislativas a nivel nacional de junio de 2009 .

Asimismo, hay consenso en la literatura que señala que luego de años donde los indicadores socioeconómicos demostraron una fuerte recuperación después de la crisis de 2001-2002, el 2008 inaugura una nueva etapa. Lindemboin (2013) sostiene que el ritmo de creación de empleo ( $18 \%$ en el primer trienio de esta década) cae a un tercio o un quinto en los trienios siguientes de la recuperación económica, impulsada por un cambio esencial en las condiciones económicas internacionales, basada en el aprovechamiento inicial de la capacidad instalada puesta en movimiento a partir de la enorme devaluación de 2002. Kessler (2014) en su análisis sobre las tendencias contrapuestas en desigualdad entre 2003-2013, observa una recuperación significativa e incontestable hasta 2007-2008 para luego señalar mayores controversias, producto sobre todo de la inflación, el peso del impuesto a las ganancias y en especial de una menor capacidad de la economía de seguir generando empleos de calidad.

Sin dudas, la capacidad de cobertura de las instituciones contributivas encuentra un claro límite cuando la creación de empleo decrece $y$ los niveles de informalidad $y$ no registración son elevados. Tomando este último punto, según indican los datos oficiales, a pesar del descenso, la informalidad ha sido relativamente impermeable al crecimiento económico e insensible a las medidas que actuaron como incentivos para reducir la informalidad y la fiscalización para penalizarla. Partiendo de un 49,1\% en 2003, hacia 2011 la informalidad laboral para el total de los ocupados (medida como el porcentaje de trabajadores no registrados en la seguridad social) se ubicaba en un $42,7 \%$, y esta tasa de incidencia alcanza el $37 \%$ de los trabajadores asalariados y el $59 \%$, entre los independientes (que corresponde a un 64\%, entre los cuentapropistas y el $20 \%$, entre los patrones) (мтеуss 2014). Justamente, medidas como la moratoria respondieron a esta problemática. Será cuatro años después (2009) cuando se genera una respuesta frente a los bajos niveles de cobertura en materia de transferencias a las familias con hijos. 
En este contexto, la agenda pública comenzó a nutrirse de temas de desigualdad, pobreza, desempleo e interrogantes sobre cómo garantizar transferencias a las familias con hijos, más allá de su participación o no en el mercado asalariado formal. Se presentaron en el Congreso Nacional, desde diversos sectores del arco político, numerosos proyectos legislativos con características disímiles pero sobre la base de una ampliación del régimen de asignaciones familiares ${ }^{12}$.

Claramente, si bien los programas sociales como el Jefas y Jefes de Hogar Desocupados o el Programa Familias habían sido pensados bajo la lógica del "mientras tanto" (es decir, como instrumentos transitorios), la evidencia señala que aún en un contexto de alto crecimiento económico y recuperación del mercado de trabajo, existía un conjunto de familias que no accedían a la cobertura por la vía de la seguridad social contributiva.

Frente a estas problemática, a lo largo de estos años se hicieron visibles un conjunto de resistencias del partido gobernante con relación a formatos de transferencias de ingresos a los hogares que impliquen un principio de distribución universal. Parte de estas resistencias eran sostenidas desde la cartera de Desarrollo Social a través de argumentos que iban desde la escasez presupuestaria, pasando por el riesgo de ocasionar una potencial inequidad (ya que la universalidad implicaría que el acceso de quienes no lo "necesitan"). Pero sobre todo ganaba terreno la visión que sostenía el trabajo como vía privilegiada para el logro del bienestar y como la única política universalizable: "Universalizar estos subsidios, aún con buenas intenciones como sostienen algunos sectores, es funcional al proyecto de no país que debemos terminar de revertir. El trabajo, nuestra productividad, el pleno empleo, son instrumentos no resignables" (мDs 2007). A esto se suma la lógica de trabajo propia de esa cartera ministerial en donde cualquier medida más universal (y por ende "impersonal") tensionaría con el valor del "contacto directo con la realidad", del

12 Con respecto a los proyectos legislativos existentes con anterioridad a la sanción de la AUH, cfr.: Carmona Barrenechea y Straschnoy (2008); Bestard et ál. (2012). "hacer", del "trabajo artesanal" en cada "territorio" (Perelmiter 2012).

Sin dudas el gobierno no debe ser comprendido como un todo homogéneo y el Ministerio de Trabajo se presentaba como un actor más permeable a ensayar algún tipo de extensión de las Asignaciones Familiares por fuera del esquema de los trabajadores asalariados registrados (Arcidiácono 2012).

TERCER PERÍODO (OCTUBRE 2009-2013): EL SURGIMIENTO DE LA ASIGNACIÓN UNIVERSAL POR HIJO PARA LA PROTECCIÓN SOCIAL

Hacia fines del tercer período se plantea una respuesta política para la problemática anteriormente descrita. Más concretamente, en octubre de 2009, se creó la Asignación Universal por Hijo para Protección Social (АUн) a través del Decreto nro. 1602/09, como un subsistema no contributivo dentro del régimen de las Asignaciones Familiares y bajo jurisdicción de anses, destinado a los trabajadores informales $y$ desocupados que no percibieran el seguro por tal condición. Un año y medio más tarde, en ocasión de la apertura de las sesiones legislativas, se anuncia la creación de la Asignación Universal por Embarazo para Protección Social (AUE) (Decreto nro. 446/11) como parte del subsistema no contributivo, creado a partir de la AUH (Pautassi et ál. 2013).

La AuH está destinada a las niñas, niños y adolescentes (de 18 años de edad, salvo el caso de hijos discapacitados que este límite desaparece) cuyas madres, padres, tutores o curadores se encuentren desocupados o se desempeñen en la economía informal por un salario menor al salario mínimo. A través de reformas sucesivas, la Asignación cubre hijas e hijos del personal de casas particulares con sueldo inferior al salario mínimo (art. 4º Resolución nro. 393/09) e hijos de trabajadores temporarios registrados del sector agropecuario. En cuanto a la nacionalidad, la Аuн presenta elevados requisitos sobre todo si se tienen en cuenta las políticas que la precedieron. Como requisito los niños $y$ adultos deben ser argentinos, naturalizados o extranjeros residentes legales por un período no inferior a tres años (Ceriani et ál. 2011). La AUE está destinada a mujeres embarazadas mientras 
que los requisitos restantes son similares a la AuH, a lo que se suma la necesaria ausencia de cobertura a través de obra social, salvo en el caso de monotributistas sociales, personal de casas particulares o trabajadores de temporada.

Hacia abril de 2013, la aun cubría 3283 656 niños, niñas y adolescentes menores de 18 años (anses 2013). Según datos oficiales, el 57\% de los receptores de la aun ya había sido receptor de un plan social nacional, provincial o municipal en los últimos 10 años (мтеyss 2014); lo que da cuenta de trayectorias personales que van consolidándose como más de una década de receptores de diferentes programas sociales.

Al igual que los típicos programas de transferencias condicionadas de ingresos, la $\mathrm{AuH}$ $y$ aUE contemplan la exigencia de condicionalidades de salud y educación, con una novedad, ya que anses retiene mensualmente el $20 \%$ de la prestación hasta que se demuestre anualmente su cumplimiento. En contextos inflacionarios, esta retención del $20 \%$ implica una pérdida del poder adquisitivo de la asignación. La acreditación da lugar al cobro de lo acumulado y a continuar percibiendo la asignación; caso contrario, la misma se suspende hasta que se subsane el incumplimiento. Esto supone un andamiaje burocrático pensado más bien para programas sociales de menor escala como el Programa Familias que precedió a la AuH y que promovía un seguimiento casi individual de las familias $y$ de los problemas de oferta pública vinculada con las condicionalidades. Con la escala que adquiere la asignación, la masificación de las condicionalidades termina fortaleciendo el costado más punitivo (la suspensión de la prestación para quienes incumplen). De hecho, según informa ANSES, en 2011 se suspendieron 221839 prestaciones, en 2012 se dieron 541 222, en 2013 fueron 691443 y 665632 para el $2014^{13}$.

Finalmente, una lectura en clave de fragmentaciones permite captar las diferencias entre prestaciones contributivas y no contributivas. Este sistema de condicionantes contrasta con las Asignaciones Familiares contributivas

13 Respuesta a pedido de información bajo Decreto $1172 / 03,10 / 9 / 2014$, ANSES, Nota DDYo nro. 1342/14 Dirección de Evaluación de Procesos de Control. que no imponen como requisito el cumplimiento de condicionalidades (salvo en los casos de la Asignación Anual por escolaridad donde se requiere presentación de certificado de alumno(a) regular del hijo(a)).

En lo que respecta al monto de la Аuн, este es equivalente al máximo valor establecido para la "zona general" ( $y$ luego existen 4 regiones geográficas) (Ley nro. 24 714), que desde junio de 2014 se fija en ars $\$ 644$ (us\$80) pero al finalizar el periodo analizado (2013) era de ARS $\$ 460^{14}$ (us $\$ 75$ ). La actualización de los montos, tanto de la AuH/AuE como de las Asignaciones destinadas a trabajadores formales $y / 0$ pasivos, dependen de una decisión política, es decir, no está establecida la regularidad de los aumentos o sistemas de ajustes (CIFRA 2014). Sin embargo, a diferencia de los programas anteriores los aumentos de la aun fueron frecuentes (cinco ocasiones desde su creación hasta 2013) $y$ equiparables de hecho con los aumentos de las Asignaciones contributivas ${ }^{15}$. Estos aspectos tienen directas implicancias sobre el potencial desmercantilizador de la medida y en los niveles de consumo de quienes se insertan débilmente en el mercado laboral, en sociedades de mercado donde uno de los mayores riesgos es el de no tener dinero.

Sin dudas, la AuH y la aue entrañan un cambio sustantivo en el campo de las políticas sociales, ya que luego de años de resistencia incluye grupos que se encontraban tradicionalmente excluidos de los mecanismos de seguridad social. En este sentido, el reconocimiento de los trabajadores informales como una categoría "en sî" a ser protegida supuso la característica más novedosa de la prestación (Lo Vuolo 2009, Mazzola 2012, y Aquín 2014). Asimismo, consolida el protagonismo de un tradicional

14 Desde entonces existieron diversas actualizaciones, siendo la última en mayo de 2014, la que llevó los montos de transferencia a $\$ 644$ por hijo y $\$ 2$ 100 por hijo con discapacidad. Para conocer un mayor detalle sobre los diversos aumentos en los tramos y tipos de asignaciones cfr. Arcidiácono et ál. 2014

Para conocer el detalle sobre los cambios en esta década en materia de Asignaciones contributivas, cfr. Arcidiácono et ál. 2014. 
instituto de la seguridad social contributiva (ANSES) en la política social en general.

Sin dudas no es tarea sencilla establecer la evolución global de la cobertura del sistema contributivo y no contributivo de transferencias a las familias, debido a la ausencia de series consolidadas de información pública disponibles. A su vez, dada la fragmentación de regímenes, no se encuentra consolidada la información sobre cuántas personas menores de 18 años y familias se encuentran cubiertas por los distintos sistemas de asignaciones familiares. Por lo pronto, se puede decir que los últimos datos oficiales de cobertura, provenientes de la enapross ${ }^{16}$ (encuesta realizada por el Ministerio de Trabajo en 2011) arrojan que el $74,5 \%$ de los menores de 18 años está cubierto por algún tipo de transferencia monetaria. Es importante destacar que cuando solo se considera al total de menores que la normativa habilita para recibir una transferencia, el 85,7\% está cubierto. El 42,5\% lo estaría por Asignaciones Contributivas, el 24,9\% por AUH $y$ con porcentajes más bajos contribuyen a la cobertura de los menores, las transferencias de otras fuentes, sobre todo pensiones $y$ otros programas sociales y la deducción del impuesto a las ganancias, con el $4 \%$ y el 3,2\%, respectivamente. Un $13,1 \%$ del total de la población de menores se encontraría excluido por la normativa para percibir transferencias monetarias y el $12,4 \%$ que estarían en condiciones de cobrar una transferencia, no lo están haciendo debido a problemas con los trámites. Interesa desglosar el $13,1 \%$ que se excluye por la normativa que se concentra en tres situaciones: hijos de monotributistas — que no reciben Asignaciones Contributivas y están excluidos de percibir AUH - $(35,1 \%)$; hijos de personas con trabajo no registrado e ingresos superiores al tope

16 Encuesta Nacional de Protección y Seguridad Social desarrollada en 2011 por el MTEYss que produjo información sobre seguridad y protección social, con una representatividad del $74,3 \%$ de la población de los aglomerados urbanos de 5000 habitantes o más (MTEYss 2014). En 2011, este colectivo alcanza la cantidad de 7,1millones de personas, lo que representa aproximadamente el $58 \%$ del total de menores de 18 años del país. fijado para percibir la АUн $(25,2 \%) ; y$ por último, hijos de asalariados registrados que cobran por encima del tope fijado para la percepción de la asignación y por debajo del piso para realizar deducciones del impuesto a las ganancias (32,6\% del total de excluidos).

\section{CONCLUSIONES}

Desde el 2003, la intervención estatal en el campo social fue consolidándose paulatinamente a través de medidas orientadas a los trabajadores asalariados registrados, quienes fueron mejorando sus condiciones en comparación con las políticas aplicadas durante los años 90. Se generaron y sostuvieron las condiciones que permitieron un crecimiento económico sostenido, donde la creación de fuentes de empleo fue un aspecto central (entre los años 2003 y 2012 se sumaron alrededor de 4,5 millones de puestos de trabajo). A la par se mejoró la situación de los trabajadores formales a través de la reapertura de las negociaciones colectivas, el aumento en las asignaciones familiares y la recuperación del salario mínimo, entre otras medidas. Sin embargo, en un esquema de bienestar atravesado históricamente por un fuerte componente contributivo, la persistencia de un elevado nivel de informalidad laboral en general y de empleo asalariado no registrado en particular, disminuyó el impacto de las mejoras en los ingresos y aumentó las brechas entre los asalariados y de estos con relación a los receptores de programas sociales. Este artículo dio cuenta de mayores resistencias políticas en lo que respecta a transferencias monetarias destinadas a familias con hijos, las que datan de fines de 2009 con la creación de la Asignación Universal para dar un salto de magnitud. Hasta ese momento eran las pNc, la oferta política disponible para cubrir solo casos extremos.

Esta década deja sin duda un aumento de cobertura en niños y adultos mayores. El eje de la discusión en materia de transferencias de ingresos se traslada a los desafíos que proponen los mecanismos que fueron utilizados para aumentar los niveles de cobertura. Como se analizó detalladamente en este artículo, a lo largo de estos diez años se configuró un esquema dual de provisión de bienestar con requisitos, 
sanciones, prestaciones, montos, criterios de permanencia diferentes para estar en el sistema contributivo, no contributivo o "semicontributivo". Esto se complejiza cuando se pone foco en la existencia de regímenes especiales $y$ provinciales en materia de seguridad social, todo lo cual tiene implicancias para los propios destinatarios de las políticas que muchas veces transitan entre un subsistema y otro.

La dimensión cuantitativa que adquieren las medidas implementadas evidencia que los componentes "no contributivo" o "semicontributivo" no tienen un carácter residual ni son parte de un "mientras tanto", más bien se consolidaron como protagónicos y estables. Prueba de ellos es que las asignaciones familiares (aquellas que son abonadas por anses) se reparten casi en estrictas partes iguales entre Asignaciones Contributivas y aUн (ANSES 2013) consolidando el rol de anses en ambos campos, sucediendo lo mismo con las prestaciones previsionales. En junio de 2014, en el Mensaje del Poder Ejecutivo al Congreso donde se propone una nueva moratoria previsional, se argumenta que las prestaciones ingresadas a partir del Plan de Inclusión Previsional (principalmente por la moratoria) representan el $45,7 \%$ de los beneficios totales del sipa y un poco más reducido el rol de las prestaciones de las PNc ${ }^{17}$ (PEN 2014).

La respuesta estatal fue la de avanzar considerablemente en cobertura tomando la decisión de sostener un esquema de ampliación de prestaciones diferenciadas para quienes no son comprendidos por los arreglos institucionales $y$ prestaciones asociadas con el trabajo formal. A pesar de su masividad ${ }^{18}$, ninguno de los arreglos

17 Tomando datos del Censo 2010 las prestaciones previsionales se repartan en partes iguales: 2,9 millones de beneficios contributivos del SIPA; 2,4 millones de beneficios por moratoria y 1,1 millones para todas las PNC (Betranou y Casanova 2013).

Debido a las particularidades de este esquema que adquiere una cobertura masiva pero sin un principio de acceso como se entendieron las políticas tradicionalmente universales es que surgen esfuerzos analíticos que derivan en un conjunto de denominaciones ad hoc. Por ejemplo, Danani y Hintze (2011) lo denominan "universalismo sui generis", al entremezclar elementos doctrinarios institucionales se basó en el principio de ciudadanía propio de los esquemas universales tradicionales (como salud y educación). Todavía el régimen de bienestar argentino presenta rigideces, que si bien a lo largo de estos años, con mayor o menor demora fueron venciéndose, se hacen evidente en la institucionalidad más débil que tienen estas medidas, cuyos principales desafíos están orientados a sostener la continuidad $y$ reducir la incertidumbre de estos arreglos institucionales en el mediano y largo plazo, a fin de mantener los altos niveles de cobertura e incluir a quienes todavía no lo están. Sin ir más lejos, la moratoria previsional, que fue la llave para la expansión de la cobertura en adultos mayores, tuvo un carácter extraordinario, puntual y no estructural; por lo cual quienes hoy trabajan en condiciones de noregistración, oportunamente encontrarán que no reúnen los requisitos para jubilarse.

La historia ha demostrado que las PNo asistenciales son muy sensibles a los altibajos políticos (pasando de congelarse hasta aumentar exponencialmente su cobertura), bajo esquemas de comprobación de recursos con mayor nivel de discrecionalidad. Por su parte, la AUH genera incertidumbre para aquellas mujeres que ingresan indirectamente a la seguridad social por su condición de madres de menores de edad, situación que es transitoria. Asimismo, no son aspectos menores tanto el surgimiento por la vía del decreto como los aumentos de los montos, los cuales tal como están formulados dependen de la voluntad política del gobierno. La discusión política sobre la continuidad y el rol de los componentes nuevos del sistema de transferencias de ingresos deben ser leídos en un contexto argentino, atravesado por la fortaleza simbólica e institucional del sistema clásico de la seguridad social, organizado a partir de la relación salarial formal. 
REFERENCIAS BIBLIOGRÁFICAS

LIBROS

Aquín, Nora. 2014. Asignación Universal por Hijo ¿Titulares o tutelados? Buenos Aires: Espacio Editorial.

Arcidiácono, Pilar. 2012. La política del "mientras tanto": Programas sociales después de la crisis 2001-2002. Buenos Aires: Biblos.

Bertranou, Fabio, Oscar Cetrángolo, Carlos Grushka y Luis Casanova. 2011. Encrucijadas en la Seguridad Social Argentina: reformas, cobertura $y$ desafíos para el Sistema de Pensiones. Santiago: oIT/CEPAL.

Bestard, Ana María, Maximiliano Carrasco y Mora Kantor. 2012. "El poder legislativo nacional y los programas sociales en el período 2002-2009”. ¿Más derechos menos marginaciones? Políticas sociales $y$ bienestar en la Argentina. Buenos Aires, Biblos-Derechos Sociales y Políticas Públicas.

Centro de Estudios Legales y Sociales (cels). 2004. Las pensiones por vejez frente al derecho a la seguridad social. Buenos Aires: cels.

Danani, Claudia y Susana Hintze, coordinadoras. 2011. Protecciones y desprotecciones: la seguridad social en la Argentina 1990-2010. Buenos Aires: Universidad Nacional de General Sarmiento.

Equipo Latinoamericano de Justicia y Género (ELA). 2011. Sistema previsional en argentina y equidad de género. Situación actual (2003-2010) y perspectivas futuras. Buenos Aires: ela, diciembre.

Isuani, Aldo y Jorge San Martino. 1995. La reforma previsional argentina. Buenos Aires: Miño y Dávila.

Kessler, Gabriel. 2014. Controversias sobre la desigualdad. Argentina 20032013. Buenos Aires: Fondo de Cultura Económica.

Lo Vuolo, Rubén y Alberto Barbeito. 1998. La nueva oscuridad de la politica social.
Del estado populista al neoconservador. Buenos Aires: Ciepp-Miño y Dávila.

Lozano, Claudio y Tomas Raffo, coordinadores. 2013. Discrecionalidad y anarquía en el Sistema de Asignaciones Familiares. Buenos Aires: Instituto de Pensamiento y Política Pública.

Mazzola, Roxana. 2012. Nuevo paradigma. La Asignación Universal por Hijo en la Argentina. Buenos Aires: Prometeo.

Ministerio de Desarrollo Social (мDs). 2007. La bisagra. Informe de Gestión 2003-2007. Buenos Aires, mDs.

Ministerio de Trabajo Empleo y Seguridad Social (мтеуss). 2003. Libro blanco de la previsión social. Buenos Aires.

Ministerio de Trabajo Empleo y Seguridad Social (мтеуss) у огт. 2012. Macroeconomía, empleo e ingresos: debates y politicas en Argentina frente a la crisis internacional 2008-2009. Buenos Aires: MTEYSS-OIT.

Salvia, Agustín. 2011. La trampa neoliberal. Heterogeneidad estructural y distribución del ingreso en la Argentina. Buenos Aires: Editorial EUDEBA.

PUBLICACIONES PERIÓDICAS

Calvi, Gabriel y Elsa Cimillo. 2010. "Del sIJP al sipa. Cambios recientes en el sistema de previsión social argentino". Tapirawi, Revista de Estudios Sobre sociedad y justicia. Julio-diciembre: 72-99.

Ceriani Pablo, Paula Cyment y Diego Morales. 2011. "Migración, derechos de la niñez y Asignación Universal por Hijo: las fronteras de la inclusión social". Acceso el 25 de agosto de 2012. http://www.derhuman. jus.gov.ar/conti/2011/10/mesa_2/ceriani_ cyment_MORALE__mesa_2.pdf

Isuani, Aldo. 1992. "Política social y dinámica política en América Latina". Desarrollo Económico, vol. xxxII, n. ${ }^{\circ}$ 152: 35-55.

Lindemboin, Javier. 2013. "Por qué se estanca el empleo". Diario Clarín. Disponible en: http://www.ieco.clarin.com/economia/ estanca-empleo_0_909509284.html

Lo Vuolo, Rubén. 2009. "Asignación por hijo". Serie de Análisis de Coyuntura, n. ${ }^{\circ} 21$. 
Rofman, Rafael y María Laura Oliveri. 2012. "Un repaso sobre las políticas de protección social y la distribución del ingreso en Argentina”. Económica, vol. LVIII. Enero-diciembre.

\section{TEXTOS ELECTRÓNICOS}

Bertranou, Fabio y Luis Casanova. 2013. "Informalidad laboral en Argentina. Segmentos críticos y políticas para la formalización". Acceso el 4 de julio de 2013. http://www.ilo.org/buenosaires/ publicaciones/wcms_234705/lang--es/ index.htm

Bosch, Mariano, Ángel Melguizo y Carmen Pagés. 2013. "Mejores pensiones, mejores trabajos. Hacia la cobertura universal en Latinoamérica y Caribe". Acceso el 1 de febrero de 2014. http://www.redetis.iipe. unesco.org/wp-content/uploads/2014/04/ Mejores-pensiones-mejores-trabajos.pdf

Ceriani, Pablo, Paola Cyment y Diego Morales. 2011. "Migración, derechos de la niñez y Asignación Universal por Hijo: las fronteras de la inclusión social". Acceso 25 de agosto de 2012. http://conti. derhuman.jus.gov.ar/2011/10/mesa_2/ ceriani_cyment_morales_mesa_2.pdf

OTROS

Administración Nacional de la Seguridad Social-Observatorio de la Seguridad Social (anses). 2013. "Asignación Universal por Hijo para Protección Social. Decreto 1602/09. Informe cuatrimestral. 1er cuatrimestre 2013". Buenos Aires. Acceso el 28 de julio 2014. http://observatorio.anses.gob.ar/archivos/ documentos/PPT\%20\%20AUH\%20I\%20 C\%202013\%20F.pdf

Arcidiácono Pilar, Gustavo Gamallo, Laura Pautassi y Mora Straschnoy. 2014. "Brechas en las prestaciones sociales. Acerca de las asignaciones familiares $y$ de la asignación universal por hijo en Argentina”. Mimeo.

Arza, Camila y Florencia Chabenderian. 2014. "Pensiones básicas en América
Latina. Diseño, cobertura y beneficios comparados en Argentina, Brasil, Bolivia y Chile". Documento de Trabajo del ciepp nro. 89. Acceso el 1 de agosto 2014. http://www.ciepp.org.ar

Bestard, Ana María, Maximiliano Carrasco y Laura Pautassi. 2014. "La cuestión federal pendiente: sistemas previsionales locales y brechas contributivas". Mimeo.

Carmona Barrenechea, Verónica y Mora Straschnoy. 2008. "El Ingreso Ciudadano para la infancia: una nueva perspectiva sobre las políticas sociales". Trabajo presentado en el Encuentro Iberoamericano de Ingreso Ciudadano, julio.

Centro de Investigación y Formación de la República Argentina (cifra). 2014. Informe de Coyuntura número 16, mayo.

Coatz, Diego, Fernando García Diaz y Sergio Woyecheszen. 2010. "Acerca de la dinámica creciente de la heterogeneidad productiva y social en la Argentina: un aporte para repensar políticas públicas a partir del análisis desde la estructura ocupacional". Boletín Informativo Techint, n. 332, mayo-agosto: 49-80.

Cogliandro, Gisell. 2013. "Pensiones no contributivas para madres de 7 ó más hijos: Seguridad social para las madres en situación de vulnerabilidad social". Boletín del observatorio de la maternidad, n. 66 , mayo.

Danani, Claudia y Estela Grassi. 2013. "El sistema de protección social argentino entre 2002 y 2013: características y nuevo problemas". Presentado en la Universidad de Buenos Aires, noviembre.

Pautassi, Laura. 2005. “Bailarinas en la oscuridad? Seguridad social en América Latina el marco de la equidad de género". Ponencia presentada en la Trigésima Octava Reunión de la Mesa Directiva de la Conferencia Regional sobre la Mujer de América Latina y el Caribe. Mar del Plata, septiembre.

Pautassi, Laura, Pilar Arcidiácono y Mora Straschnoy. 2013. Asignación Universal por Hijo para Protección Social de la Argentina. Entre la satisfacción de 
necesidades y el reconocimiento de derechos. División de Políticas Sociales, CEPAL, número 184. Santiago, julio.

Perelmiter, Luisina. 2012. "Burocracia, pobreza y territorio. La política espacial de la asistencia en la Argentina reciente". Presentado en la Universidad Nacional de General Sarmiento, 24 y 25 de abril.

Ministerio de Trabajo, Empleo y Seguridad Social (мтеss). 2012. Boletín Estadístico de la Seguridad Social. II trimestre 2012. Secretaría de Seguridad Social.
Ministerio de Trabajo, Empleo y Seguridad Social (мтеss). 2014. Resultados de la Encuesta Nacional de Protección y Seguridad Social 2011 1a ed. Argentina: мтEss.

Poder Ejecutivo Nacional. 2014. Mensaje al Poder Legislativo por segunda etapa del Plan de Inclusión previsional. 16 de junio.
Fecha ingreso: $31 / 10 / 2014$ Fecha aprobación: 03/06/2015 
